\title{
Variation of sperm length and heteromorphism in drosophilid species
}

\author{
D. Joly, M.-L. Cariou, D. Lachaise and J.R. David
}

Centre National de la Recherche Scientifique, laboratoire de biologie et génétique évolutives, 91198 Gif-sur-Yvette Cedex, France

(received 8 December 1988, accepted 17 April 1989)

Summary - Sperm length was measured in 27 drosophilid species, and a general survey of size variation is presented for 75 species for which information is available. Mean length varies from $0.113 \mathrm{~mm}$ in the $D$. obscura group to almost $20 \mathrm{~mm}$ in the recently investigated $D$. littoralis; in the latter case, sperm length is nearly 6 times the male body length. The huge interspecific variability may be estimated by considering the coefficient of variation (c.v.) between species belonging to the same taxon. In the genus Drosophila the c.v. amounts to $130 \%$ (64 species). The average c.v. decreases in lower taxa, being for example $96 \%$ in subgenera and $61 \%$ in species groups. More closely related species are thus less divergent, but in any case sperm length must be considered as a fast evolving trait, increasing or decreasing. Individual measurements of sperm length within a species generally provide a unimonal, relatively gaussian distribution (monomorphism). By contrast, 13 investigated species of the $D$. obscura group exhibited bimodal distributions. This heteromorphism may be considered as a stable evolutionary strategy in the $D$. obscura group.

Drosophila - sperm length - sperm heteromorphism - sperm evolution

Résumé - Variation de la longueur des spermatozoïdes et hétéromorphisme chez les drosophilidés. La longueur des spermatozoïdes mesurés chez 27 espèces de Drosophilidés est étudiée au niveau de l'ensemble de la famille (75 espèces). Les moyennes de longueur varient de $0,113 \mathrm{~mm}$ chez les espèces du groupes obscura jusqu'à $20 \mathrm{~mm}$ chez une espèce nouvellement étudiée, D. littoralis; chez cette dernière, la longueur du spermatozoïde atteint 6 fois la longueur du corps de l'adulte. L'amplitude de la variation interspécifique peut être appréciée en considérant le coefficient de variation (c.v.) entre espèces appartenant à un même taxon. Dans le genre Drosophila (64 espèces étudiées), la valeur du c.v. atteint $130 \%$. Les valeurs des c.v. moyens diminuent pour les niveaux taxonomiques inférieurs, c'est-à-dire $96 \%$ au niveau du sous-genre et $61 \%$ pour les groupes d'espèces. Les longueurs de spermatozoïdes des espèces étroitement apparentées sont relativement proches mais dans quelques cas, il apparaît que ce caractère évolue rapidement, tendant, soit à augmenter, soit à diminuer. Les mesures de la longueur des spermatozoïdes pour une espèce correspondent généralement pour un individu à une distribution unimodale, gaussienne (monomorphisme). En revanche, les 13 espèces du groupe obscura montrent des distributions bimodales. Cet hétéromorphisme peut être considéré comme une stratégie évolutive stable.

Drosophile - longueur des spermatozoïdes - hétéromorphisme des spermatozoïdes évolution des spermatozoïdes 


\section{INTRODUCTION}

In most Eucaryote species, meiotic reproduction has evolved in producing two sizes of gametes, known as the macro, or female gamete (oocyte or ovum) and the micro, or male gamete (sperm) respectively (Parker et al., 1972; Power, 1976; Maynard Smith, 1978; Alexander \& Borgia, 1979; Parker, 1984). In the macrogamete, size variations between taxa are well documented and incorporated in the evolutionary theories of parental investment (Trivers, 1972) and life history strategies (Throckmorton, 1966).

By comparison, evolutionary trends in the microgamete (sperm) have remained neglected. Indeed, when considering vertebrates an overall uniformity seems the rule, yet some differences in sperm heads or tails have been found in rabbits and rodents (Friend, 1936; Beatty \& Napier, 1960; Beatty \& Sharma, 1960; Woolley, 1971). In these, sperm with a medium size flagellum less than $0.1 \mathrm{~mm}$ long are produced in huge numbers and each gamete has an extremely low probability of producing a zygote. Sperm shape, size and ultrastructure are, however, far more diverse among invertebrates (Fain-Maurel, 1966; Afzelius et al., 1976; Baccetti, 1979; Sivinski, 1984; Chauvin et al., 1988) and analysing this diversity should help to understand the developmental constraints and selective pressures which permitted or promoted the various patterns presently observed. In some invertebrates, including Lepidoptera, two or more morphologically and functionally different microgametes occur intraspecifically and warrant recognition of eusperm and parasperm (Healy \& Jamieson, 1981; Jamieson, 1987a).

In the present work, attention is focused on the evolution of sperm length in a monophyletic dipteran taxon, the family Drosophilidae. Drosophila melanogaster, generally considered as a reference for this group, is known for its long sperm $(1.9 \mathrm{~mm})$ which is almost as long as the body of the fly (Cooper, 1950; Yanders \& Perras, 1960; Beatty \& Burgoyne, 1971; Gould-Somerot et al., 1974; Joly, 1987). However, at the family level, $D$. melanogaster sperm can appear very short compared to those of other species such as for instance $D$. hydei, where it can be 4-5 times (1.4 or even $1.9 \mathrm{~cm}$ ) the size of the body of the fly (Hess \& Meyer, 1963; Jamieson, 1987b).

Taxonomists have long been aware that, in the family Drosophilidae, sperm length could be very variable between species and several papers have been recently devoted to this problem (Beatty \& Sidhu, 1970; Sanger \& Miller, 1973; Gromko et al., 1984; Sivinski, 1984; Hatsumi \& Wakahama, 1986; Hihara \& Kurokawa, 1987; Joly, 1987). Explaining such variations raises an evolutionary challenge which may be formulated as follows: if sperm length is a fast evolving trait, it should exhibit a high genetic variance and a high heritability, at least in some species; moreover, a rapid evolution for increased or decreased length would be difficult to explain if the trait is considered as neutral, and strong selective pressures should exist or have existed during the process of speciation.

In Drosophila, intraspecific genetic variability of sperm length is poorly documented and presently available investigations have failed to demonstrate genetic variance (Joly, 1987) or have found only very limited variability (Beatty \& Sidhu, 1970; Sanger \& Miller, 1973). The aim of this paper is to focus attention on interspecific variations and to present an overview of what is known in the family. 
In the genus Drosophila, sperm length can indeed be considered as a fast evolving trait with a loose relationship with phylogeny. In most species, sperm length distributions within the individual are unimodal with a limited variability. However, in one monophyletic taxon, the $D$. obscura species group, the occurrence of bimodal distributions seems the rule and we therefore argue here that it corresponds to an evolutionary stable strategy (ESS) (Maynard Smith, 1974).

\section{MATERIAL AND METHODS}

Sperm length was measured in 27 species, 13 of which belong to the obscura species group including the two recently discovered East African species (D. microlabis and D. kitumensis) (Cariou et al., 1988). The source of material of the obscura group species investigated was the same as in Cariou et al. (1988) with the exception of D. affinis (14012, 014-1) and D. azteca (14012-0171) which were provided by the Bowling Green Stock.

The eight species of the melanogaster subgroup were analyzed. The source of specimens of the melanogaster complex species was the same as in Joly (1987) while those of the others were the following: $D$. teissieri and $D$. yakuba came from different localities in Africa (Gif Stock); D. erecta (Ivory Coast, Gif 220-5) and D. orena (West Cameroon, Gif 188-1).

Other drosophilid species studied were D. bahunde (Kenya, Gif 269-4), D. bakundjo (Kenya, Gif 269-5), Scaptomyza pallida (Kenya, Gif 292-2), Zaprionus tuberculatus (West-Africa), D. grimshawi (Hawaii) and D. littoralis (unknown Palearctic origin) from the Bowling Green Stock.

The strains were reared at $21^{\circ} \mathrm{C}$. Sperm were recovered from the seminal vesicles of one or several males. The testes were isolated and opened in a drop of saline solution and the sperm allowed to spread out. This preparation was observed under a microscope with phase contrast optics. When the sperm had ceased to move, they were traced with the aid of a camera lucida and the trace lengths measured with a cursor on a digitizing table connected to a microcomputer. Except for the obscura group species, the measure of cyst length was preferred to that of sperm length to minimise the risk of breakage. All details of this method are given in Joly (1987 and 1989).

The sperm length of the 48 other species belonging to different taxa of the Drosophilidae are provided in the literature (Sanger \& Miller, 1973; Hatsumi \& Wakahama, 1986; Hihara \& Kurokawa, 1987).

\section{RESULTS}

Results for the investigated species are given in Table I and for the 13 species of the D. obscura group in Table III. Some of the species presented in these tables have already been studied by other investigators, for example $D$. melanogaster (Table IV) and some species in the $D$. obscura group. Our measurements are, on the whole, in good agreement with previous data in spite of methodological problems mainly due to the difficulty in obtaining identifiable and unbroken cells. It is therefore possible to present (Table II) a general overview of size variability across the entire Drosophilidae family. 
Table I. Biometrical data of sperm length (cysts) for species investigated other than those of the D. obscura group.

\begin{tabular}{lrrrr}
\hline Species & $n$ & $m$ & s.e. & $c . v$. \\
\hline Drosophila SG Sophophora & & & & \\
D. melanogaster & 150 & 1.898 & .008 & 5.3 \\
D. simulans & 350 & 1.124 & .002 & 4.3 \\
D. mauritiana & 200 & 1.036 & .004 & 5.7 \\
D. sechellia & 200 & 1.649 & .008 & 7.7 \\
D. yakuba & 1200 & 1.681 & .008 & 13.5 \\
D. teissieri & 1300 & 1.606 & .008 & 19.9 \\
D. erecta & 50 & 1.210 & .004 & 2.4 \\
D. orena & 50 & 1.436 & .006 & 3.4 \\
D. bahunde & 1 & 3.144 & - & - \\
D. bakundjo & 1 & 3.173 & - & - \\
Drosophila s. str. & & & & - \\
D. littoralis & 1 & 19.297 & - & 5.1 \\
D. grimshawi & 57 & 1.664 & .011 & 16.6 \\
Zaprionus tuberculatus & 8 & 3.729 & .218 & 3.6 \\
Scaptomyza pallida & 17 & 1.257 & .011 & \\
\hline
\end{tabular}

$n=$ number of sperm measured; $m=$ mean of sperm length in millimeters; s.e. $=$ standard error; c.v. = coefficient of variation.

At a genus level, mean length varies from 0.63 (Amiota) to $5.32 \mathrm{~mm}$ (Mycodrosophila). However, among the 75 species presently studied, 64 belong to the Drosophila genus which is itself characterized by a huge interspecific heterogeneity. A more detailed analysis according to taxonomic subdivisions is presented in the lower part of Table II. The best documented subgenera, Drosophila and Sophophora, exhibit significant sperm length variations, with means of 5.03 and $1.14 \mathrm{~mm}$ respectively. Also, within each subgenus, lower taxa, i.e. species groups, may have different lengths and variations. For example, in Drosophila, flies in the D. immigrans group have much shorter sperm than in both the $D$. repleta and $D$. virilis groups which are characterized by very long sperm; the record length is provided here by $D$. littoralis from the latter group where it reaches $2 \mathrm{~cm}$, that is 6 times the body length (Table I). In Sophophora, we may further contrast the $D$. melanogaster and the $D$. obscura species groups with means of 1.45 and $0.30 \mathrm{~mm}$ respectively.

Another way of analysing the data is to consider the heterogeneity among species belonging to taxa of similar levels. Since mean lengths are so variable, variances cannot be used directly and a relative measure, the coefficient of variation (c.v.) has therefore been preferred. This analysis is limited to Drosophila, since other genera are poorly documented. On the other hand, the Drosophila genus comprises so many species (over 1500 ) that taxonomists felt the need for a series of hierarchical subdivisions, as defined, for example, by Bock \& Wheeler (1972) 
Table II. Biometrical data for different taxa, genus (G), subgenus (SG), group (gr.) and subgroup (sgr.).

\begin{tabular}{|c|c|c|c|c|c|c|}
\hline & & & & & & \\
\hline & $N$ & $m$ & s.e. & c.v. & $\min$ & $\max$ \\
\hline Genera of Drosophilidae & & & & & & \\
\hline G. Amiota & 2 & 0.63 & 0.01 & 1.1 & 0.63 & 0.64 \\
\hline G. Leucophenga & 3 & 1.20 & 0.09 & 14.7 & 1.08 & 1.38 \\
\hline G. Drosophila & 64 & 2.50 & 0.40 & 130.2 & 0.11 & 19.00 \\
\hline G. Liodrosophila & 1 & 2.47 & - & - & - & - \\
\hline G. Mycrodrosophila & 1 & 1.06 & - & - & - & - \\
\hline G. Mycodrosophila & 1 & 5.32 & - & - & - & - \\
\hline G. Scaptomyza & 2 & 0.92 & 0.34 & 52.0 & 0.58 & 1.25 \\
\hline G. Zaprionus & 1 & 3.73 & - & - & & \\
\hline Genus Drosophila & & & & & & \\
\hline SG. Dorsilopha & 1 & 1.10 & - & - & - & - \\
\hline SG. Drosophila & 22 & 5.03 & 0.93 & 87.2 & 1.27 & 19.00 \\
\hline immigrans gr. & 10 & 2.67 & 0.39 & 47.0 & 1.27 & 5.06 \\
\hline nasuta sgr. & 8 & 2.85 & 0.46 & 45.9 & 1.27 & 5.06 \\
\hline quinaria gr. & 2 & 3.36 & 2.37 & 20.6 & 2.87 & 3.85 \\
\hline repleta gr. & 2 & 12.00 & 2.00 & 23.6 & 10.00 & 14.00 \\
\hline robusta gr. & 2 & 5.36 & 3.09 & 2.0 & 5.29 & 5.44 \\
\hline virilis $g r$ & 2 & 12.70 & 6.26 & 69.8 & 6.47 & 19.00 \\
\hline SG. Hirtodrosophila & 3 & 2.06 & 0.85 & 71.7 & 0.36 & 3.04 \\
\hline SG. Scaptodrosophila & 4 & 0.86 & 0.41 & 96.4 & 0.21 & 2.02 \\
\hline SG. Sophophora & 34 & 1.14 & 0.20 & 103.5 & 0.12 & 5.37 \\
\hline dentissima $g r$. & 2 & 3.15 & 0.05 & 2.2 & 3.10 & 3.20 \\
\hline melanogaster gr. & 14 & 1.93 & 0.28 & 55.6 & 1.00 & 5.37 \\
\hline melanogaster sgr. & 8 & 1.45 & 0.12 & 23.6 & 1.00 & 1.90 \\
\hline montium sgr. & 2 & 3.79 & 1.57 & 58.8 & 2.22 & 5.37 \\
\hline obscura gr. & 18 & 0.30 & 0.06 & 95.8 & 0.11 & 1.07 \\
\hline affinis sgr. & 7 & 0.53 & 0.13 & 68.1 & 0.17 & 1.07 \\
\hline microlabis sgr. & 2 & 0.13 & 0.01 & 11.3 & 0.12 & 0.14 \\
\hline obscura sgr. & 7 & 0.15 & 0.01 & 20.1 & 0.11 & 0.20 \\
\hline pseudoobscura sgr. & 2 & 0.16 & 0.01 & 4.3 & 0.16 & 0.17 \\
\hline
\end{tabular}

$N=$ number of species; $\min =$ smaller sperm length values; $\max =$ higher sperm length values in millimeters. Other abbreviations as in Table I.

who recognized subgenera, species groups, species subgroups, and within the latter, species complexes, species "clusters", and pairs or groups of sibling species.

At the genus level, the overall c.v. is $130 \%$ (Table II) which means that the standard deviation is higher than the mean and the actual distribution is strongly skewed towards high values. Considering lower level taxa leads to lower values of c.v., i.e. $96 \%, 61 \%$ and $34 \%$ respectively for subgenera, species groups and species subgroups. It appears that homogeneity increases when more closely related species are compared.

It has been shown that intraspecific genetic variability in sperm length is poorly documented in Drosophila and requires further investigation. However, within each 
species, the shape of the distributions of individual sperm measurements is worthy of consideration, and examples of such distributions are given in Figure 1. In $D$. melanogaster and $D$. simulans the distributions are obviously unimodal and close to a gaussian curve. Such is not the case in species of the D. obscura group, which exhibit clear-cut disjoint distributions. This intraspecific and intraindividual heterogeneity was already known in some of these species and the word polymegaly, meaning several sizes, was coined to describe this situation (Beatty \& Sidhu, 1970; Beatty \& Burgoyne, 1971). Our results confirm and extend these observations. In some cases, such as $D$. pseudoobscura, it could be argued that, by visual inspection, several peaks may be recognized. However, no statistical method exists for counting the number of peaks in a distribution. On the other hand, visual inspection always shows a well defined peak for short sperm while the situation may be more complex for longer sperm. As a conservative measure, it was decided to differentiate only two size classes in each species, i.e. short and long sperm, the size limit between the two classes being in most cases easy to define. Morphometric data, analysed in this way, are presented in Table III for the 13 investigated species of the $D$ obscura group.

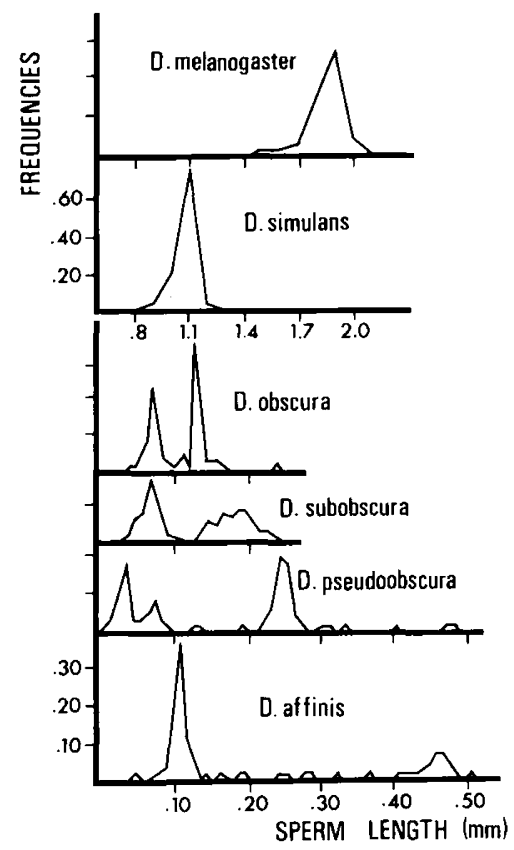

Fig. 1. Sperm length distributions for two sibling species of the $D$. melanogaster subgroup (above) and for four species of the $D$. obscura group. Note the different scale between the two taxa.

The shorter sperm class is variable in proportion from 30 to $88 \%$ of the distribution, but the average value is close to $50 \%$. In several species, e.g. D. pseudoobscura, the short sperm has a length of about $0.050 \mathrm{~mm}$, close to the usual 
size of mammals. The interspecific variation ranges between 0.056 and $0.143 \mathrm{~mm}$. By contrast, the long sperm class is more variable, ranging from 0.139 to $0.925 \mathrm{~mm}$, and is also more heterogenous, as shown by its high c.v. When the two classes are pooled, the bimodality of the distributions is evidenced by the very high c.v. : $53 \%$.

Table III. Biometrical data for short and long sperm classes within the D. obscura species group.

\begin{tabular}{|c|c|c|c|c|c|c|c|c|c|c|c|}
\hline \multirow{2}{*}{ SPECIES } & \multirow[b]{2}{*}{$n$} & \multirow[b]{2}{*}{$\%$} & \multicolumn{2}{|c|}{$\begin{array}{c}\text { shorter } \\
\text { sperm }\end{array}$} & \multirow[b]{2}{*}{ limit } & \multicolumn{2}{|c|}{$\begin{array}{l}\text { longer } \\
\text { sperm }\end{array}$} & \multicolumn{2}{|c|}{ Total } & \multicolumn{2}{|c|}{ Range } \\
\hline & & & $m$ & c.v. & & $m$ & c.v. & $m$ & c.v. & $\min$ & $\max$ \\
\hline \multicolumn{12}{|l|}{ affinis subgroup } \\
\hline D. azteca & 97 & 88 & 143 & 12.6 & 202 & 925 & 41.9 & 240 & 121.0 & 102 & 1339 \\
\hline D. affinis & 305 & 69 & 112 & 7.1 & 131 & 424 & 21.5 & 177 & 79.6 & 53 & 535 \\
\hline $\begin{array}{l}\text { D. helvetica } \\
\text { microlabis subgroup }\end{array}$ & 356 & 42 & 100 & 12.0 & 139 & 223 & 10.3 & 170 & 37.5 & 44 & 262 \\
\hline D. kitumensis & 200 & 70 & 87 & 10.3 & 103 & 248 & 14.9 & 135 & 56.8 & 52 & 319 \\
\hline $\begin{array}{l}\text { D. microlabis } \\
\text { obscura subgroup }\end{array}$ & 200 & 62 & 68 & 14.7 & 104 & 196 & 14.3 & 115 & 56.3 & 33 & 263 \\
\hline D. bifasciata & 200 & 30 & 83 & 19.3 & 123 & 228 & 12.3 & 185 & 38.2 & 44 & 293 \\
\hline D. guanche & 200 & 49 & 131 & 7.6 & 157 & 273 & 9.5 & 202 & 26.4 & 107 & 344 \\
\hline D. madeirensis & 200 & 64 & 137 & 10.2 & 167 & 218 & 11.0 & 166 & 26.0 & 81 & 284 \\
\hline D. obscura & 83 & 42 & 76 & 11.8 & 112 & 139 & 13.7 & 113 & 31.2 & 40 & 170 \\
\hline D. subobscura & 210 & 48 & 85 & 15.3 & 128 & 199 & 12.6 & 142 & 42.3 & 50 & 255 \\
\hline D. tristis & 200 & 64 & 112 & 10.7 & 147 & 235 & 8.9 & 152 & 39.8 & 55 & 274 \\
\hline pseudoobscura subgrc & & & & & & & & & & & \\
\hline D. persimilis & 200 & 50 & 67 & 25.4 & 113 & 244 & 17.2 & 158 & 59.8 & 30 & 315 \\
\hline D. pseudoobscura & 244 & 45 & 56 & 37.5 & 109 & 263 & 14.4 & 168 & 63.7 & 20 & 285 \\
\hline $\begin{array}{l}\mathrm{m} \\
\text { s.e. }\end{array}$ & & $\begin{aligned} 57 & \\
4.3 & \end{aligned}$ & $\begin{array}{l}97 \\
7.8\end{array}$ & $\begin{array}{r}15.0 \\
2.3\end{array}$ & & $\begin{array}{l}293 \\
55.6\end{array}$ & $\begin{array}{r}15.6 \\
2.4\end{array}$ & $\begin{array}{r}163 \\
9.6\end{array}$ & $\begin{array}{r}53.0 \\
7.0\end{array}$ & & \\
\hline
\end{tabular}

$\%=$ percentage of sperm of the short class; limit $=$ threshold value chosen between short and long classes. Other abbreviations as in Table I and II. Data are given in $10^{-3}$ millimeters.

\section{DISCUSSION AND CONCLUSION}

The great length of the sperm of numerous drosophilid species raises some technical problems concerning length determination: very elongated flagella are easily broken during dissection and, taking into account incomplete cells, would both decrease the calculated mean and increase the variance.

For that reason, measurement of mature cysts, assumed to give more reliable data, was preferred in our study for species with longer sperm, e.g. in $D$. melanogaster. This method in addition to the use of saline solution instead of fixatives, probably explains the discrepancies between our data and some of those 
previously published (Table IV). For extreme lengths of over one centimeter, found for example in $D$. littoralis and $D$. hydei, even the cysts are often broken so that it is very difficult to evaluate intraspecific variability. However, it seems reasonable to conclude that shorter values correspond to incomplete cysts and to consider only the longer measurements as typical of the species.

In contrast, there are no technical difficulties in having complete short sperm which do not break easily. Therefore, the heteromorphism of the distributions in the $D$. obscura group species, which has already been observed by previous investigators (Yanders \& Perras, 1960; Beatty \& Sidhu, 1970; Policansky, 1970; Beatty \& Burgoyne, 1971; Sanger \& Miller, 1973; Kurokawa et al., 1974) cannot be accounted for by any technical bias.

Table IV. Synopsis of all sperm length values in millimeters published for D. melanogaster (cysts in Joly, 1987; sperm in all other references).

\begin{tabular}{lrllrr}
\hline Authors & Date & Strain & Method & Length & Nb \\
\hline Cooper & 1950 & & & 1.760 & 5 \\
Yanders \& Perras & 1960 & Oregon-R & acetic formalin & 1.751 & 13 \\
Hess \& Meyer & 1963 & XO & & 1.100 & \\
& & XY & & 1.750 \\
& & XYY & & 3.700 & \\
Beatty \& Sidhu & 1970 & Oregon-K & aceto-orceine & 1.840 & 1 \\
Beatty \& Burgoyne & 1971 & Oregon-K & giemsa; aceto-orceine & 1.720 & 49 \\
Gould-Somerot et al. & 1974 & XY Canton-S & saline solution & 1.920 & 6 \\
& & XYY & with & 1.860 & 5 \\
& & XYT (Y; 3) & 9\% fetal & 1.850 & 5 \\
& & XYY & calf serum & 1.690 & 7 \\
Joly & 1987 & Ivory Coast & ringer solution & 1.846 & 50 \\
& & South Africa & ringer solution & 1.933 & 50 \\
& & France & ringer solution & 1.915 & 50 \\
& & & &
\end{tabular}

The occurrence of very long male gametes in numerous Drosophila species raises several evolutionary questions, to be discussed below. The first concerns the ancestral or primitive state of sperm length. According to theories of modern cladistic systematics, this may be inferred by considering taxonomic outgroups. There are very few cases of animals with such relatively giant sperm. Among these are featherwing beetles (Coleoptera, Ptiliidae) (Dybas \& Dybas, 1981; Taylor, 1982) or some ostracods (Bauer, 1940) where sperm may be several times the male length (see review in Sivinski, 1984; Jamieson, 1987b). Nevertheless, species with sperm of inordinate length are still more common in fruit flies. A reasonable proposal is therefore that short sperm are primitive while long sperm are derived (Hihara \& Kurokawa, 1987). However, the situation is less clear at a lower level; in the $D$. melanogaster species complex, for instance (Table I), sperm length distributions appear to be divergent in most closely related species (e.g. D. simulans cf. $D$. sechellia), but convergent in less closely related species (e.g. D. sechellia cf. D. 
melanogaster). Here if phylogeny is considered (Cariou, 1987) we must conclude that elongation occurred independently during the speciation process. A similar reasoning could be applied in comparing other taxa in which there are species with either short or long sperm. Unfortunately, knowledge of Drosophila phylogenies does not presently allow such comparison. Whatever the conclusions might be, it remains clear that evolution and speciation in the family Drosophilidae is characterized by a general tendency towards increasing sperm length, as already assumed by Hihara \& Kurokawa (1987).

This overall evolutionary tendency further suggests that size variation is not random but has been subject to natural selection (Joly, 1989). The most important questions that then arise are: how and why did sperm elongation evolve? Some insights may be gained by considering the heteromorphism of the D. obscura group species.

Clearly, heteromorphism, which is typical of the whole group, is genetically determined (Beatty \& Sidhu, 1970). Moreover, this does not correspond to a genetic polymorphism at the diploid level, since any single male produces heteromorphic sperm. Nor is it a case of gametic polymorphism since all the sperm cells, included in the same cysts, and which could be genetically different, exhibit the same length. Heteromorphism seems to be more a case of polyphenotypism which is determined by some unknown physiological mechanisms at the cyst level. A reasonable interpretation is that heteromorphism is an evolutionary stable strategy (ESS) (Maynard Smith, 1974), each sperm class having some adaptive advantage. For instance, the short and long sperm may have differential capacities both to reach the storage organs (preemption capacity) and to resist the second male paragonial substances (antipreemption capacity) when a female remates. A precise formulation of such a hypothesis, which requires comparison of the evolution of both sperm length and mating systems in different species, is proposed in a forthcoming paper.

\section{REFERENCES}

Afzelius B.A., Baccetti B. \& Dallai R. (1976) The giant spermatozoon of Notonecta. Submicrosc. Cytol. 8, 149-161

Alexander R.D. \& Borgia G. (1979) On the origin and basis of the male-female phenomenon. In: Sexual Selection and Reproductive Competition in Insects. (Blum M.S. \& Blums N.A., eds), Academic Press, New York, 417-440

Baccetti B. (1979) Ultrastructure of sperm and its bearing on arthropod phylogeny. In: Arthropod Phylogeny (Gupta A.P., ed.), Van Nostrand Reinhold, New York, 609642

Bauer H. (1940) Uber die Chromosomen der bisexuallen und der parthenogenetischen Rasse des Ostracoden Heterocyris incongruens Ramd. Chromosoma 1, 620637

Beatty R.A. \& Burgoyne P.S. (1971) Size classes of the head and flagellum of Drosophila spermatozoa. Cytogenetics 10, 177-189

Beatty R.A. \& Napier R.A.N. (1960) Genetics of gametes II - Strain differences in characteristics of rabbit spermatozoa. Proc. R. Soc. Edinb. Sec. B. 68, 17-24 
Beatty R.A. \& Sharma K.N. (1960) Genetics of gametes. III - Strain differences in spermatozoa from eight inbred strains of mice. Proc. R. Soc. Edinb. Sec. B. 68, 25-53

Beatty R.A. \& Sidhu N.S. (1970) Polymegaly of spermatozoan length and its genetic control in Drosophila species. Proc. R. Soc. Edinb. Sec. B. 71, 14-28

Bock I.R. \& Wheeler M.R. (1972) I. The Drosophila melanogaster species group. Univ. Tex. Publ. 7213,1-102

Cariou M.L. (1987) Biochemical phylogeny of the eight species in the Drosophila melanogaster subgroup, including $D$. sechellia and D.orena. Genet. Res. Camb. 50, 181-185

Cariou M.L., Lachaise D., Tsacas L., Sourdis J., Krimbas C. \& Ashburner M. (1988) New African species in the Drosophila obscura species group: genetic variation, differentiation and evolution. Heredity 61,73-84

Chauvin G., El Agoze M., Hamon C. \& Huignard J. (1988) Ultrastructure des spermatozoïdes des mâles haploïdes et diploïdes de Diadromus pulchellus Wesmeal (Hymenoptera: Ichneumonidae), Int. J. Morphol. Embryol. 17, 359-366

Cooper K.W. (1950) Normal spermatogenesis in Drosophila. In: Biology of Drosophila (Demerec M. ed.) 1-61, New York, Wiley

Dybas L.K. \& Dybas H.S. (1981) Coadaptation and taxonomic differentiation of sperm and spermathecae in featherwing beetles. Evolution 35, 168-174

Fain-Maurel M.A. (1966) Acquisitions récentes sur les spermatogenèses atypiques. Ann. Biol. (11-12), 513-564

Friend G.F. (1936) The sperms of the British Muridae. Q. J. Microsc. Sci. 78, 419-443

Gould-Somerot M., Hardy R. \& Holland L. (1974) The Y chromosome and sperm length in D. melanogaster. Exp. Cell. Res. 87, 397-398

Gromko M., Gilbert D.G. \& Richmond R.C. (1984) Sperm tranfer and use in the multiple mating system of Drosophila. In: Sperm Competition and The Evolution of Animal Mating Systems (Smith R.L. ed.), Academic Press, Orlando, 371-426

Hatsumi M. \& Wakahama K.I. (1986) The sperm length and the testis length in Drosophila nasuta subgroup. Jpn. J. Genet. 61, 241-244

Healy J.M. \& Jamieson B.G.M. (1981) An ultrastructural examination of developing and mature paraspermatozoa in Pyrazus ebeninus (Mollusca, Gastropoda, Potamididae). Zoomorphology 98, 101-119

Hess O. \& Meyer G.F. (1963) Chromosomal differentiations of the Lampbrush type formed by the Y chromosome in Drosophila hydei and Drosophila neohydei. J. Cell. Biol. 16, 527-539

Hihara F. \& Kurokawa H. (1987) The sperm length and the internal reproductive organs of Drosophila with special references to phylogenetic relationships. Zool. Sci. $4,167-174$

Jamieson B.G.M. (1987a) A biological classification of sperm types, with special reference to annelids and molluscs, and an example of spermiocladistics. In: New Horizons in Sperm Cell Research (Mohri H. ed.) Japan Science Society Press, Gordon and Breach Scientific Publications, New York, 311-332 
Jamieson B.G.M. (1987b) The Ultrastructure and Phylogeny of Insect Spermatozoa. Camb. Univ. Press

Joly D. (1987) Between species divergence of cyst length distributions in the Drosophila melanogaster species complex. Jpn. J. Genet. 62, 257-263

Joly D. (1989) Diversité des spermatozoïdes et compétition spermatique chez les Drosophila. Thèse, Doctorat, Univ. Paris XI

Kurokawa H., Matsuo Y. \& Hihara F. (1974) A study on sperm length and body size of Drosophila bifasciata. Ann. Zool. Japonenses 47, 140-146

Maynard Smith J. (1974) The theory of games and the evolution of animal conflicts. J. Theor. Biol. 47, 209-221

Maynard Smith J. (1978) The evolution of sex. Cambridge University Press, Cambridge

Parker G.A. (1984) Sperm competition and the evolution of animal mating strategies. In: Sperm Competition and the Evolution of Animal Mating Systems (Smith L.S. eds) Academic Press, Orlando, 1-60

Parker G.A., Baker R.R. \& Smith V.G.F. (1972) The origin and evolution of gamete dimorphism and the male-female phenomenon. J. Theor. Biol. 36, 529-553

Policansky D. (1970) Three sperm sizes in D. pseudoobscura and D. persimilis. D.I.S. 45,119

Power H.W. (1976) On forces of selection and the evolution of mating types. Am. Nat. 110, 937-944

Sanger W.G. \& Miller D.D. (1973) Spermatozoan length in species of the Drosophila affinis subgroup. Am. Midl. Nat. 90,4859

Sivinski J. (1984) Sperm in competition. In: Sperm Competition and The Evolution of Animal Mating System (Smith R.L. ed.) Academic Press, Orlando, 85-115

Taylor V.A. (1982) The giant sperm of a minute beetle. Tissue Cell 14, 113-123

Throckmorton L.H. (1966) Relationships of Hawaiian Drosophilidae. Univ. Tex. Publ. 6615, 364-396

Trivers R.L. (1972) Parental investment and sexual selection. In: Sexual selection and the descent of man 1871-1971, (Campbell B. ed.). Univ. of California, LA, Aldine, Chicago, 136-179

Woolley D.M. (1971) Selection for the length of the spermatozoan midpiece in the mouse. Genet. Res. Cam. 16, 261-275

Yanders A.F. \& Perras J.P. (1960) Sperm length in four Drosophila species. D.I.S. 34,112 